\title{
Relative humidity at Armagh Observatory, 1838-2008
}

\author{
C. J. Butler* and A. M. García-Suárez \\ Armagh Observatory, College Hill, Armagh BT61 9DG, N. Ireland
}

\begin{abstract}
We present a calibrated atmospheric humidity series for Armagh Observatory, Northern Ireland. Beginning in 1838 and continuing to the present day, this series is believed to be the longest presented so far. Daily wet-bulb and dry-bulb temperature readings are corrected for the time of reading and for known instrumental errors to determine mean monthly, seasonal and annual relative humidity (RH) at 09:00 GMT from 1838 to 2008 and at 21:00 GMT from 1844 to 1964 .

The mean seasonal and annual time series of RH at this site show only marginal evidence for a trend in $\mathrm{RH}$ since the 1880s, however, there is significant decadal and multi-decadal variability, some of which appears to be cyclic. Wavelet analysis indicates the presence of two quasi-periodic components in $\mathrm{RH}$, one ranging from 23.4 to 25.5 years and the other from 36 to 51 years. We discuss potential physical origins of these cycles such as changes in the atmospheric and thermohaline circulation and the solar magnetic cycle. There is a small but significant anti-correlation between RH and northerly winds.

Two conspicuous peaks in RH during the 19th century coincide with major infestations of potato blight in Ireland. Copyright (C) 2011 Royal Meteorological Society
\end{abstract}

KEY WORDS Northern Ireland; humidity; wet-bulb and dry-bulb temperatures; time series; oscillations

Received 14 May 2010; Revised 16 November 2010; Accepted 11 January 2011

\section{Introduction}

Water vapour is constantly cycling through the atmosphere, evaporating from ocean and land surfaces, condensing into clouds and subsequently returning to the ground as precipitation. These processes, known as the hydrological cycle, are crucial to the Earth's climate. Whilst water vapour is also the most abundant of the greenhouse gases, exceeding $\mathrm{CO}_{2}$ and other minor constituents of the atmosphere by several times in its greenhouse contribution (Tyndall, 1861; Trenberth et al., 2007), and critical for the habitability of the planet, its possible variability over recent centuries has received little attention compared to temperature and precipitation (also: Manabe and Wetherald, 1967; Kiehl and Trenberth, 1997; Held and Soden, 2000; Soden et al., 2005).

Relative humidity (RH) is one of the parameters used to quantify water vapour in the atmosphere. It has been usually measured since the early 19th century by readings from a matched pair of wet-bulb and drybulb thermometers. Though such data are common, they require careful calibration for known instrumental errors and the time of reading. For these and other reasons, extended series are rare. It is believed this may be the first long humidity series to be presented.

* Correspondence to: C. J. Butler, Armagh Observatory, College Hill, Armagh BT61 9DG, N. Ireland. E-mail: cjb@arm.ac.uk

\section{Data}

A description of the site of Armagh Observatory $\left(54^{\circ} 21^{\prime} 8.82^{\prime \prime},-6^{\circ} 38^{\prime} 58.50^{\prime \prime}\right)$ and its environment has been given by Butler et al. (2005a). In general, though situated within the boundaries of a small historic cathedral city, its predominantly rural surroundings have ensured that there are no detectable urban climatic effects (Coughlin and Butler, 1998).

Meteorological observations began at Armagh Observatory in 1796 , continued throughout the 19th and 20th centuries (with a gap from 1825 to 1833), and are now some of the longest-running sets of observations from a single site in the British Isles. The climate series for this site have been standardised taking into account all known metadata surviving in the Armagh Observatory and UK Meteorological Office (UKMO) archives. The published series include: precipitation (Butler et al., 1998; GarcíaSuárez et al., 2002), air temperature (Butler et al., 2005a; 2005b; 2005c); soil temperatures (García-Suárez and Butler, (2006); García-Suárez et al., 2005); and hours of bright sunshine (Pallé and Butler, 2001; Butler et al., 2005d). This paper extends the Armagh series to include relative humidity. Additional papers on atmospheric pressure, specific humidity, wind strength and direction are planned.

Daily wet-bulb and dry-bulb temperature readings in the morning commenced, initially sporadically, in January 1836, gradually improving in regularity until 1840. From that year, to the present day, they are 
largely complete (García-Suárez et al., 2007). Additional evening readings were made from January 1844 to March 1965. The uncalibrated wet-bulb and dry-bulb temperature data are contained in manuscript form in M117 of the Armagh Observatory Archives (Butler and Hoskin, 1987) and can be accessed electronically via the Armagh Observatory Climate website (http://climate.arm.ac.uk).

Before and after entry into computer file, considerable effort was taken to ensure accuracy of the raw daily data. In the first instance, the meteorological observer, who was normally a permanent member of staff at the Observatory, registered the daily readings. These were monitored by the director of the Observatory who was invariably a competent scientist and frequently a specialist in meteorology. From 1868 to the present day, monthly reports have been submitted to the UK Meteorological Office (UKMO) for further quality control, details of which are preserved at the Public Record Office for Northern Ireland (PRONI) and at Armagh Observatory (García-Suárez et al., 2005). If at any stage a discrepancy was spotted by the UKMO, this was communicated back to the observer and the record amended. As a part of this study, the UKMO reports at PRONI have been examined, and differences between the Observatory and UKMO records, where present, investigated. On rare occasions when an error is suspected and cannot be traced, the observation for that day is excluded.

Occasionally in winter, prior to 1868 , when the wet bulb was frozen no readings were recorded and no RH is available for these days. Later, it became standard practice to record the wet-bulb and dry-bulb readings even when frozen. On such occasions, RH can be computed using different equations (Sec. 3.4).

\section{Homogenisation of the data series}

Since wet-bulb and dry-bulb thermometer readings began in 1836 there have been several changes in equipment, exposure and the time of observation that could lead to inhomogeneities in the series.

Here we describe known sources of inhomogeneity in the series and our procedure for their elimination. Other, unrecognised, sources of inhomogeneity could conceivably remain.

\subsection{Correction for instrumental error}

Fortunately, wet-bulb and dry-bulb thermometers, unlike maximum and minimum thermometers, do not need to be reset after reading. They are, therefore, less prone to accidental damage and can continue in use for long periods. In addition, with RH dependent on the difference between two matched thermometers, instrumental errors in either of them should be quickly detected through a systematic shift in the depression of the wet bulb relative to the dry bulb. This has effectively ensured that the thermometers were monitored for any calibration changes that may have developed over the period of use.
From January 1836 until 31 December 1884, the wet-bulb and dry-bulb thermometer readings at Armagh were made with a hygrometer manufactured by Jones of London. No calibration data has been found for this early instrument, and therefore, no instrumental corrections are applied. From 1 January 1885 a new hygrometer, supplied by the UKMO, was incorporated in a Stevenson Screen. Henceforth, instruments were supplied with calibration certificates and checked from time to time for accuracy by a UKMO inspector. Only systematic errors in temperature reported by the inspector have been corrected - occasional sporadic differences of the order of $0.1{ }^{\circ} \mathrm{C}$ (the measuring error), that did not repeat at successive inspections, were ignored. The thermometers in use since 1836 and the instrumental corrections applied to the raw data are listed in Table I. Interpolation between corrections is made when they are known to be temperature dependent.

\subsection{Correction for exposure}

Butler et al. (2005a) have described the location and exposure of the maximum and minimum and wet-bulb and dry-bulb thermometers used at Armagh Observatory in the first half of the 19th century. Initially, the instruments were placed in a bright metal box which was situated in a north-facing window of the 1827 East Tower. This effectively shielded the thermometers from sunshine and allowed free circulation of air. From 1 January 1885 the thermometers were moved to a Stevenson Screen on the South Lawn of the Observatory where they have remained. A comparison of mean air temperatures measured in the bright metal box and the Stevenson Screen carried out between December 2003 and October 2004 showed only a very small systematic difference in mean temperature $\left(\sim 0.2^{\circ} \mathrm{C}\right)$. As relative humidity depends on the difference between a matched pair of thermometers, we do not expect this small difference in temperature to affect RH.

Nevertheless, unlike the mean air temperature, maximum and minimum temperatures were found to differ significantly from those in the Stevenson Screen in the sense that values were less extreme at the window of the East Tower. This was probably due to the close proximity of masonry. On average, $\mathrm{RH}$ reaches its extremes at similar times to local air temperature, i.e. a minimum in early afternoon and a maximum several hours after midnight. Readings of the hygrometer, on the other hand, were made at times (09:00 and 21:00 GMT) intermediate between the extremes and thus, like mean air temperature, should not be seriously affected by changes in the extremes.

As a further check on the homogeneity of the RH series before and after the installation of the Stevenson Screen we have searched for a discontinuity in the average annual RH between intervals of two and five years prior to and following the move. For the twoyear means, the differences are $-0.2 \%$ for the morning series, and $1.2 \%$ for the evening. For the five-year means, 
Table I. List of corrections for wet-bulb and dry bulb thermometers.

\begin{tabular}{|c|c|c|c|}
\hline \multicolumn{2}{|c|}{ Dry Bulb } & \multicolumn{2}{|c|}{ Wet bulb } \\
\hline $\begin{array}{l}\text { Thermometer } \\
\text { Temp. range }\end{array}$ & $\begin{array}{l}\text { Period used/correction } \\
\text { applied (deg. F) }\end{array}$ & $\begin{array}{l}\text { Thermometer } \\
\text { temp. range }\end{array}$ & $\begin{array}{l}\text { Period used/correction } \\
\text { applied (deg. F) }\end{array}$ \\
\hline Jones & $\begin{array}{l}1 \text { Jan } 1836-31 \text { Dec } 1884 \\
\text { None }\end{array}$ & Jones & $\begin{array}{c}1 \text { Jan } 1836-31 \text { Dec } 1884 \\
\text { None }\end{array}$ \\
\hline No. 3256 & 1 Jan $1885-31$ Dec $1899^{a}$ & No. 3254 & 1 Jan $1885-31$ Dec $1899^{a}$ \\
\hline$\leq 32 \mathrm{~F}$ & -0.1 & $\leq 32 \mathrm{~F}$ & -0.1 \\
\hline $32-42 \mathrm{~F}$ & -0.2 & $32-42 \mathrm{~F}$ & -0.2 \\
\hline $42-72 \mathrm{~F}$ & -0.1 & $42-72 \mathrm{~F}$ & -0.1 \\
\hline$\geq 72 \mathrm{~F}$ & -0.1 & $\geq 72 \mathrm{~F}$ & -0.2 \\
\hline No. 3256 & 1 Jan 1900-2 Aug 1909 & No. 3254 & 1 Jan $1900-2$ Aug $1909^{\mathrm{b}}$ \\
\hline$\leq 32 \mathrm{~F}$ & -0.3 & $\leq 32 \mathrm{~F}$ & -0.3 \\
\hline $32-42 \mathrm{~F}$ & -0.2 & $32-42 \mathrm{~F}$ & -0.2 \\
\hline $42-72 \mathrm{~F}$ & -0.3 & $42-72 \mathrm{~F}$ & -0.3 \\
\hline$\geq 72 \mathrm{~F}$ & -0.3 & $\geq 72 \mathrm{~F}$ & -0.2 \\
\hline No. 8087 & 3 Aug 1909-29 Feb 1972 & No. 8088 & 3 Aug 1909-29 Feb 1972 \\
\hline$\leq 32 \mathrm{~F}$ & 0.0 & $\leq 32 \mathrm{~F}$ & 0.0 \\
\hline $32-52 \mathrm{~F}$ & 0.0 & $32-52$ & 0.0 \\
\hline $52-72 \mathrm{~F}$ & -0.1 & $52-72 \mathrm{~F}$ & -0.1 \\
\hline$\geq 72 \mathrm{~F}$ & 0.1 & $\geq 72 \mathrm{~F}$ & -0.1 \\
\hline No. 76825 & $\begin{array}{l}1 \text { Mar 1972-present } \\
\text { None }\end{array}$ & No. 77111 & $\begin{array}{l}1 \text { Mar 1972-present } \\
\text { None }\end{array}$ \\
\hline
\end{tabular}

${ }^{\text {a }}$ Corrections were applied before entering into the record books.

${ }^{\mathrm{b}}$ Corrections applied from 1900 to Aug 1909 were those from the calibration certificate plus a further correction of $-0.4 \mathrm{~F}$ as recommended by the inspector.

the differences are -2.0 and $-1.4 \%$ respectively. If a discontinuity in RH were to be present between 1884 and 1885 as a result of the shift in position of the hygrometer, these four differences should be of the same sign and similar magnitude. In fact, the difference between the means, (for both two-year and five-year intervals), lack any consistency in sign or magnitude. Furthermore, the differences are mostly less than the standard deviation of the annual means (1.7\%). Incorrect adjustment of the raw values to account for a presumed inhomogeneity can also be a source of error and so, without strong overwhelming evidence for a discontinuity, we consider it unwise to take steps that may introduce more error. For the above reasons, no correction to $\mathrm{RH}$ for the change in exposure has been made.

In Section 4, we draw attention to an apparent discontinuity in the evening series in the first decade of the 20th century for which no cause has been found in the metadata.

\subsection{Correction for the time of reading}

Unlike exposure, the time of reading is expected to have a significant effect on the measurement of humidity. This is because, as mentioned above, RH has an appreciable diurnal variation. Normally, $\mathrm{RH}$ changes fastest between 08:00 and 10:00 GMT in the morning, and 18:00 and 20:00 GMT in the evening; that is close to the time of morning and evening readings. The morning observation times have varied from 09:00 to 10:27 GMT over the period covered by the series due to changes from local
Armagh time to Dublin time, and finally to GMT (Table I of Butler et al., 2005a). There was a similar shift in evening observation times which were always $12 \mathrm{~h}$ after the morning readings.

A very similar problem was encountered in the calculation of an equivalent daily mean air temperature from twice daily air temperature observations. Such data are commonly employed to extend instrumental temperature series to the period before reliable maximum and minimum thermometers were available. The problem was solved by Butler et al. (2005a) for the Armagh temperature series using corrections derived from mean diurnal temperature curves established with hourly readings from a self-recording thermograph maintained at Armagh Observatory from 1868 to 1883 . This problem does not affect mean temperatures determined from maximum and minimum thermometers for which the time of reading is less critical. A basically similar correction method is employed here for $\mathrm{RH}$.

Our correction of the RH series proceeds as follows: (1) to correct the raw wet-bulb and dry-bulb thermometer readings for instrumental error; (2) to calculate the $\mathrm{RH}$ from the wet-bulb and dry-bulb readings for the time of observation according to the procedure outlined in the following section; (3) to adjust the measured value for the difference in humidity at 09:00 and 21:00 GMT and the actual time of reading by reference to mean diurnal humidity curves. Further details of this final correction stage are given in Section 3.5. 
3.4. Calculation of relative humidity from wet-bulb and dry-bulb temperatures

The relative humidity $(R H)$ is the ratio of the amount of water vapour in the air, $\mathrm{e}(T)$, to the amount that it can hold when the air is saturated, es $(T)$, multiplied by 100 . At the dry-bulb temperature, we have

$$
R H=100 \mathrm{e}\left(T_{\mathrm{db}}\right) / \mathrm{es}\left(T_{\mathrm{db}}\right) .
$$

For the determination of $R H$, from Jensen et al. (1990) and Harrison (1965), we note that: under normal conditions with the wet-bulb temperature above $0^{\circ} \mathrm{C}$, $\mathrm{e}\left(T_{\mathrm{db}}\right)$ depends on both the dry-bulb and the wet-bulb temperatures $T_{\mathrm{db}}$ and $T_{\mathrm{wb}}$ according to the relation

$$
\mathrm{e}\left(T_{\mathrm{db}}\right)=\mathrm{es}\left(T_{\mathrm{wb}}\right)-A \cdot P\left(T_{\mathrm{db}}-T_{\mathrm{wb}}\right)
$$

where: $P$ is the mean atmospheric pressure in $\mathrm{kPa}$ (assumed to be $101.3 \mathrm{kPa}$ ), $A$ is the conversion factor

$$
A=0.00066\left(1.0+0.00115 T_{\mathrm{wb}}\right)
$$

and es $\left(T_{\mathrm{db}}\right)$ and es $\left(T_{\mathrm{wb}}\right)$ are expressed in terms of $T_{\mathrm{db}}$ and $T_{\mathrm{wb}}$ as follows:

$$
\begin{aligned}
& \operatorname{es}\left(T_{\mathrm{db}}\right)=\exp \left\{\left(16.78 T_{\mathrm{db}}-116.9\right) /\right. \\
& \left.\quad\left(T_{\mathrm{db}}+237.3\right)\right\} \\
& \operatorname{es}\left(T_{\mathrm{wb}}\right)=\exp \left\{\left(16.78 T_{\mathrm{wb}}-116.9\right) /\right. \\
& \left.\quad\left(T_{\mathrm{wb}}+237.3\right)\right\}
\end{aligned}
$$

Occasionally, during winter months, the wet-bulb temperature falls below $0^{\circ} \mathrm{C}$ and it is necessary to replace the last equation for the saturation vapour pressure over liquid water with one for the saturation vapour pressure over ice. In these circumstances, we use the equation by Buck (1981) as quoted by Vomel (2010):

$$
\operatorname{es}\left(T_{\mathrm{wb}}\right)=0.61115 \exp \left\{22.452 T_{\mathrm{wb}} /\left(272.55+T_{\mathrm{wb}}\right)\right\}
$$

Note that the approximations inherent in these equations limit the accuracy in computed RH to $\pm 2 \%$. In the selection of the above equations from a number available in the literature (Vomel, 2010; Murphy and Koop, 2005) we have compared the calculated RH values with those listed in the UKMO Hygrometric Tables (1964) which, following correspondence with the UKMO (private communication 2010), we have adopted as standard. In deciding which of the various alternative equations we should use, we took agreement with the UKMO tables over the range in air temperature seen at Armagh $\left(-10<\mathrm{T}<30^{\circ} \mathrm{C}\right)$ as the test criterion. There was excellent agreement $(<1 \%$ in $\mathrm{RH})$ for wet bulb temperatures above freezing point using equations (4) and (5), and reasonably good agreement $(<2 \%$ in $\mathrm{RH})$ below freezing point using Equations (4) and (6).

\subsection{Correction of $\mathrm{RH}$ for the time of reading}

As previously mentioned, changes in the time of observation can have a systematic effect on the derived values of $\mathrm{RH}$ due to the rapid change in $\mathrm{RH}$ at this time. A correction procedure, which relies on previously determined mean diurnal RH curves for Armagh Observatory, has been used here to transform the measured $\mathrm{RH}$ to that which would have been measured at 09:00 GMT and 21:00 GMT. The diurnal humidity curves are formed from hourly wet-bulb and dry-bulb temperature readings by the Self-Recording Thermograph which operated at Armagh Observatory from 1868 to 1883 as part of a network of automatic weather stations set up by the Board of Trade. This instrument, of which a contemporary working model can be seen at Valentia Observatory, County Kerry, was described in a Report of the Meteorological Committee of the Royal Society (1867). As for the first years of operation, only graphical data were available to us, we use here the data for the years 1874-1883 which were tabulated monthly by Scott (1874-1883). An engraving of the Self-Recording Thermograph at Armagh was published in Figure 1 by Butler et al. (2005a).

To form the diurnal humidity curves, first mean hourly humidity values are computed for each day of the year for the ten years 1874-1883. As these define humidity curves that are still rather erratically variable (due to too small a sample size) they are further averaged over a 15day interval, that is, including data for the 7 days prior to and the 7 days following the appropriate day, plus the day itself. Each hourly datum point on the curve is now the mean of 150 individual readings of RH. These curves are found to vary smoothly throughout the year (Figure 1 for examples).

In order to transform the measured RH in the morning to the equivalent at 09:00 GMT, we effectively move
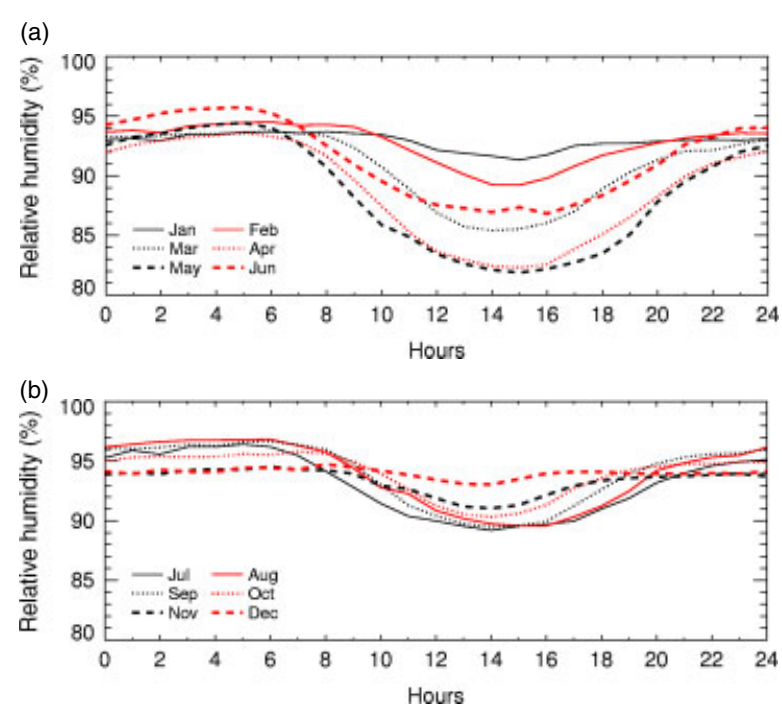

Figure 1. Mean diurnal humidity curves for the 15th day of each month from the Self-Recording Thermograph operated by the Board of Trade at Armagh Observatory from 1868 to 1883. (a) January to June, (b) July to December. This figure is available in colour online at wileyonlinelibrary.com/journal/joc 
the mean curve for the appropriate date vertically to fit the measurement at the time of reading and read off the equivalent value at 09:00 GMT. A similar procedure is used to correct the evening readings to 21:00 GMT. Though on any particular day, this procedure may not give the correct value, because actual as opposed to mean, $\mathrm{RH}$ curves are so variable, it should remove any systematic bias due to the time of reading, and therefore, allow the computation of meaningful monthly, seasonal and annual averages. No correction is made for the time of reading after 1 June 1938, the date from which all observations have been made at 09:00 and 21:00 GMT.

It should be noted that the correction procedure for the time of observation depends on the shape of the mean $\mathrm{RH}$ curves, not their mean level. As their shape depends primarily on the diurnal temperature curves (which in turn depend on the altitude of the Sun), we do not expect to see any long-term changes in shape and RH curves determined from measurements over a specific ten-year interval (1874-1883) should be applicable to the whole series.

\subsection{Daily RH}

The daily, mean monthly, seasonal and annual RH values for the period 1838-2008, which are corrected for all known instrumental errors and the time of reading, are tabulated by Butler and García-Suárez (2010) and are available from the Armagh Observatory climate website http://climate.arm.ac.uk.

Figure 2 shows daily, corrected, RH values plotted against day number together with the mean curve for both the morning and evening series. A minimum in RH in late spring of about $79 \%$ is followed by a broad maximum near $89 \%$ which lasts throughout the winter months.

Over the 171 years (>62000 days) covered by the Armagh morning humidity series, only 12 days have RH $<40 \%$ and only 90 days have RH $<50 \%$. Most of these occur in spring or early summer, the driest time of the year. Approximately $99 \%$ of all daily values lie between 60 and $100 \%$ RH.

\subsection{Comparison with neighbouring meteorological} stations

As a check on our data standardisation procedures, we have compared the RH at 09:00 GMT from Armagh Observatory with that for the nearest UKMO station at Loughall, County Armagh (54 24'28.46", $\left.-6^{\circ} 35^{\prime} 30.89^{\prime \prime}\right)$. This station, which has operated at its current site since 1995, is situated approximately $11 \mathrm{~km}$ NNE of Armagh Observatory in the grounds of a former agricultural research station. The exposure of the Loughall and Armagh meteorological stations is similar with both placed close to the top of a small drumlin. However, the altitude of the Armagh site $(62 \mathrm{~m})$ exceeds that of Loughall $(37 \mathrm{~m})$ by $25 \mathrm{~m}$.

In Figure 3, we show the mean monthly RH at Armagh Observatory together with the mean monthly RH from Loughall for the period 1996-2005, kindly supplied by the UKMO. We note the closely similar behaviour of the mean RH at the two sites, over the period in common,
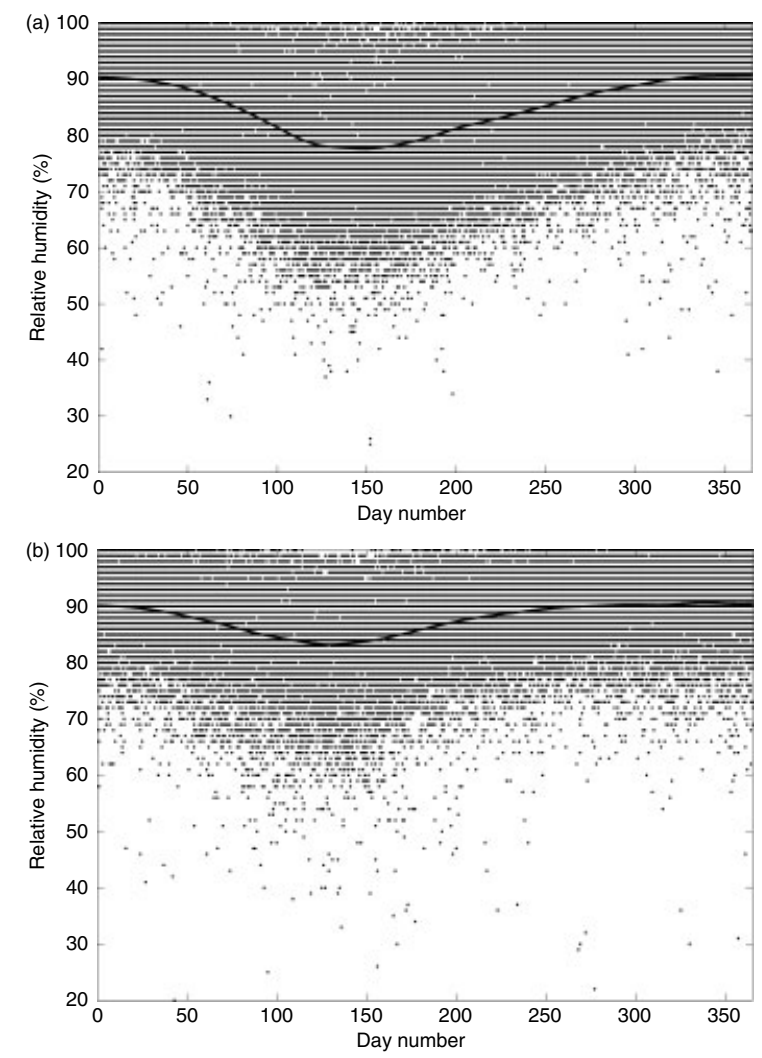

Figure 2. Daily corrected RH plotted against day number. (a) RH at 09:00 GMT, 1838-2008; (b) RH at 21:00 GMT, 1844-1964. The mean curves are running means with a Gaussian profile filter of 10 days half-width.

though there are some differences in the amplitude of the annual variation with the mean summer $\mathrm{RH}$ at Armagh systematically higher than at Loughall. This is most likely a result of the differences in altitude, topography and vegetation at the two sites. There is little or no difference in mean RH at the two sites in winter.

An attempt to compare with the longer running UKMO station at Aldergrove Airport, $44 \mathrm{~km} \mathrm{NE}$ of Armagh, was not successful due to several significant changes in the location of the meteorological enclosure there and in the type of equipment employed.

\subsection{Mean seasonal and annual RH at Armagh}

In Table II we show the mean seasonal and annual RH over various extended periods in the morning and evening series at Armagh together with the standard deviation from the mean (rms deviation). We take $1884 / 1985$ as a break point as it marks the change in exposure from a North Wall Screen to a Stevenson Screen even though there is little or no evidence for a discontinuity in $\mathrm{RH}$ at this time (Sec. 3.2). For the morning series, we include the standard climatic reference period 1961-1990.

We note: (1) That seasonal means stay within the range $79-92 \%$ with a minimum in spring or summer and a maximum in autumn or winter; (2) The standard deviation from the mean is highest in spring and summer; (3) In summer, RH is, on average $6-7 \%$ higher in the evening (21:00 GMT) than in the morning (09:00 


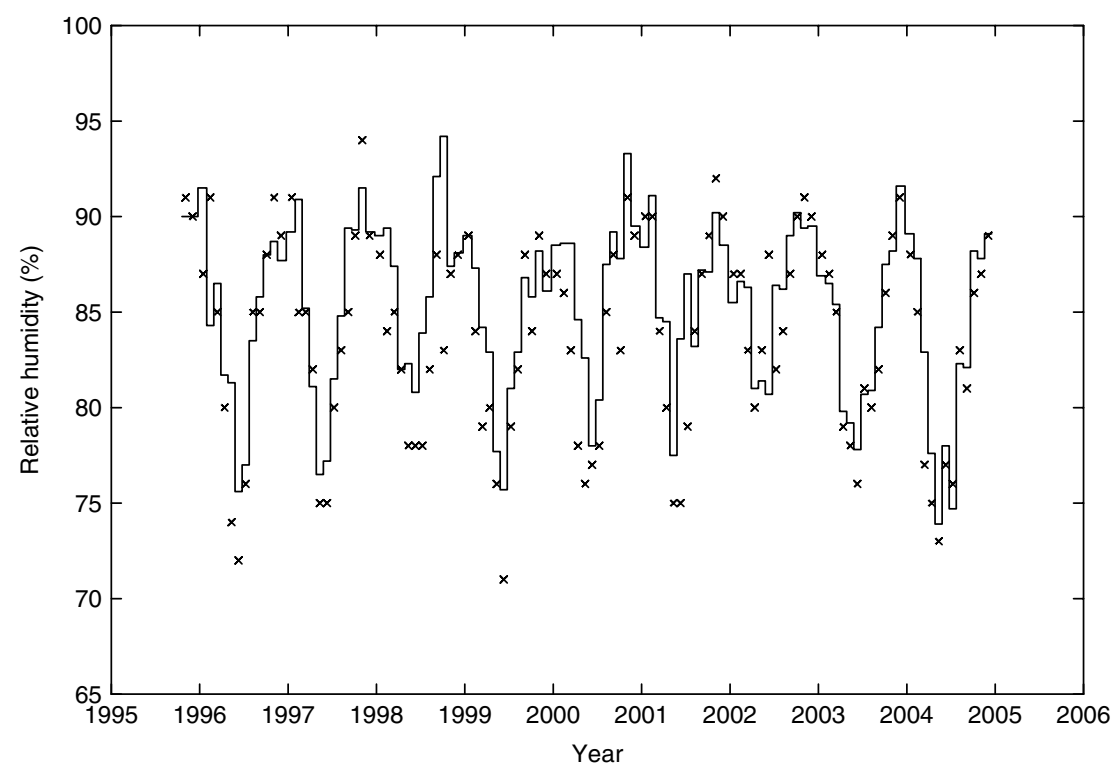

Figure 3. Comparison of mean monthly RH at Armagh Observatory and Loughall meteorological stations 1996-2005; histogram - Armagh; crosses - Loughall.

Table II. Mean seasonal and annual relative humidity and standard deviation from the mean.

09:00 GMT

\begin{tabular}{lrrrrr}
\hline Period & Winter & Spring & Summer & Autumn & Annual \\
\hline 1838-2008 & 89.8 & 81.1 & 80.8 & 88.1 & 85.0 \\
Stand. dev. & 1.7 & 2.6 & 2.9 & 1.8 & 1.7 \\
1838-1884 & 89.7 & 79.8 & 79.0 & 87.7 & 84.2 \\
Stand. Dev & 1.8 & 2.7 & 3.4 & 1.7 & 1.9 \\
1885-2008 & 89.8 & 81.6 & 81.4 & 88.3 & 85.3 \\
Stand. dev. & 1.6 & 2.3 & 2.2 & 1.7 & 1.4 \\
1961-1990 & 90.4 & 82.9 & 81.7 & 89.4 & 86.1 \\
Stand. dev. & 1.7 & 1.9 & 2.0 & 1.5 & 1.4 \\
\hline
\end{tabular}

\section{$21: 00$ GMT}

\begin{tabular}{lrrrrr}
\hline Period & Winter & Spring & Summer & Autumn & Annual \\
\hline 1844-1964 & 89.7 & 84.6 & 86.8 & 90.1 & 87.8 \\
Stand. dev. & 1.8 & 2.6 & 2.1 & 1.7 & 1.6 \\
1844-1884 & 90.3 & 85.8 & 88.1 & 91.2 & 88.9 \\
Stand. dev. & 1.5 & 2.1 & 1.9 & 1.4 & 1.2 \\
1885-1964 & 89.3 & 84.0 & 86.2 & 89.6 & 87.3 \\
Stand. dev. & 1.8 & 2.7 & 1.9 & 1.7 & 1.6 \\
\hline
\end{tabular}

GMT). This is also evident in the mean diurnal humidity curves in Figure 1; and (4) Differences between longterm averages for the same season are generally less than $3 \%$.

\section{Humidity time series}

In Figure 4, we show the time profiles of the morning and evening, seasonal and annual, mean humidity at Armagh. There are some similarities and some differences between the morning and evening series:
(1) Firstly, we note that the mean annual RH at 09:00 GMT is more or less flat from 1880 to 2008 which would suggest that there has been little systematic change in mean $\mathrm{RH}$ at this site over the past 130 years. To further explore whether or not there are any significant trends in $\mathrm{RH}$ we have subjected the morning and evening, annual and seasonal, series to simple regression analysis (Table III). Taking the whole data series (1838-2008), all morning series except winter, have a slight positive trend with an increase in $\mathrm{RH}$ of about $1 \%$ per century. However, if we exclude all data before 1885 , the trend in the morning annual series drops by half. On the other hand, for the evening series (1844-1964), in all seasons we find a slight negative trend with a fall in $\mathrm{RH}$ averaging about $1.5 \%$ per century. Bearing in mind the accuracy of RH measurements (circa 2\%) and the cyclic variability discussed later, we consider these trends to be only marginally different from zero.

(2) Many of the year-to-year differences in the morning series are closely paralleled by those in the evening series, over the period in common. This suggests that much of the year-to-year variability in both series is real.

(3) There appears to be some quasi-cyclic behaviour in both series with peaks around 1845, 1880, 1920 and 1970 which we will discuss further in the next section.

(4) It is noticeable that the year 1846, which marked the peak of the great potato famine in Ireland (caused by the humidity-sensitive fungus Phytophthora Infestans, ÓGráda, 1989), lies in the first period of high $\mathrm{RH}$ in the morning series. A second major outbreak of potato blight occurred in the late 1870 s during the second $19^{\text {th }}$-century humidity peak. 


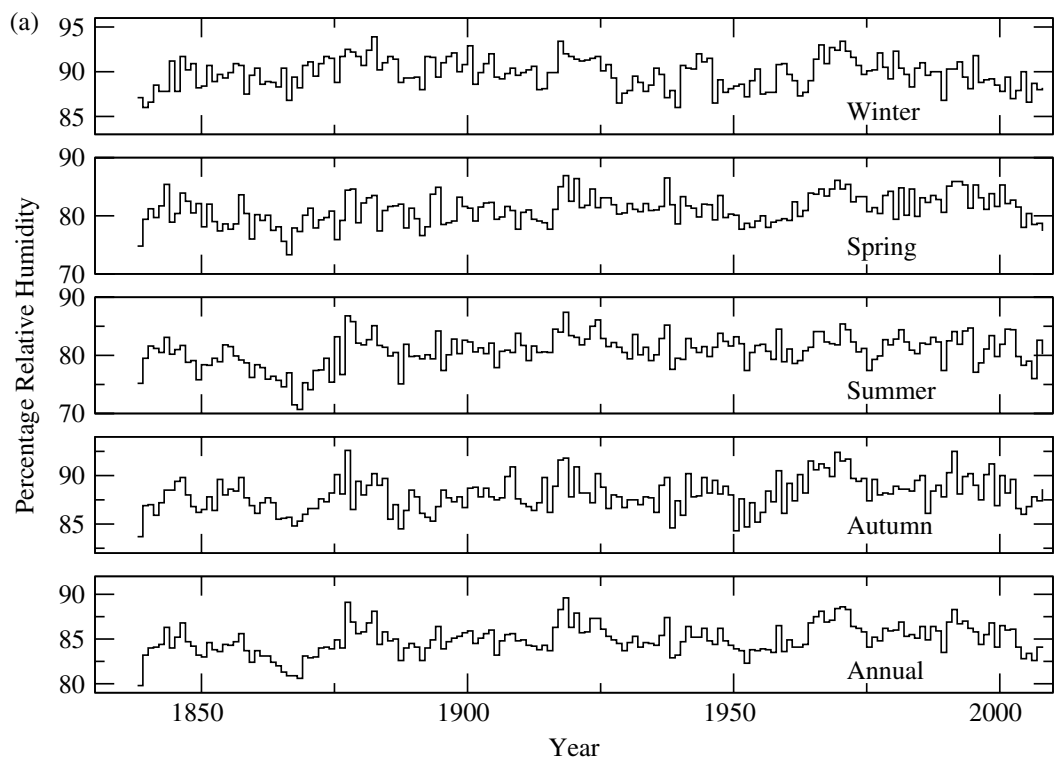

(b) $\begin{aligned} & 95 \\ & 90 \\ & 85\end{aligned}$

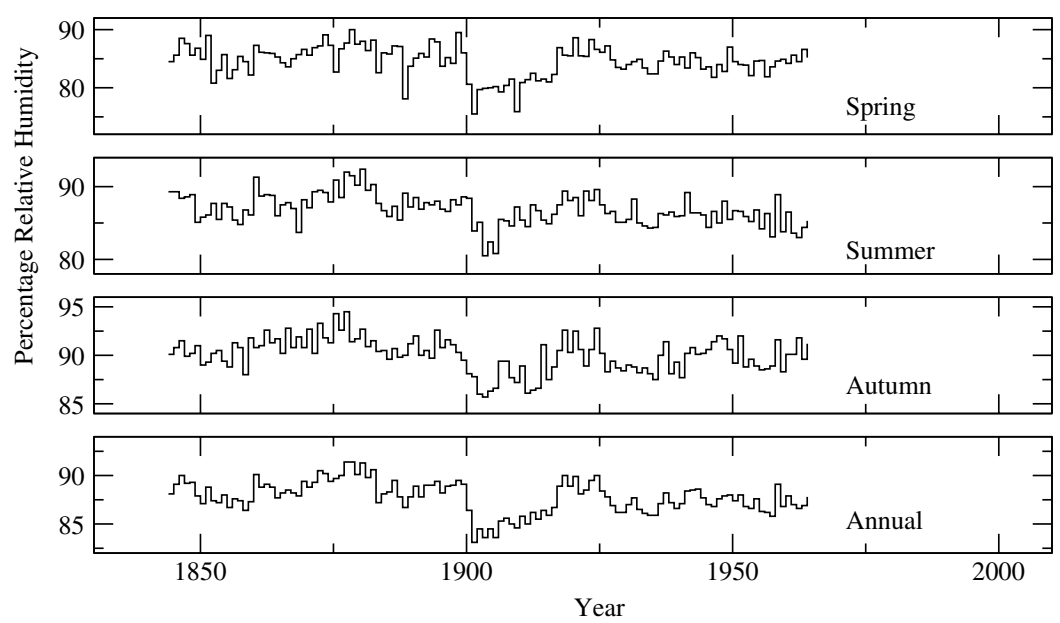

Figure 4. The time profiles of mean seasonal and annual RH at Armagh Observatory: (a) at 09:00 GMT, 1838-2008; (b) at 21:00 GMT, 1844-1964. Note that similar periodic fluctuations are present in all panels but are most clearly seen in the annual means in bottom panel of (a).

Table III. Long-term trends in relative humidity (a.m.).

\begin{tabular}{llrrrr}
\hline Duration & Season & $\begin{array}{r}\text { Slope } \\
\% \text { pa }\end{array}$ & $\begin{array}{c}\text { Stand. } \\
\text { error }\end{array}$ & $\begin{array}{r}\text { 95\% Confidence } \\
\text { limits }\end{array}$ & $\mathrm{R}$ \\
\hline $1838-2008$ & Winter & $-0.001 \pm 0.003$ & -0.006 to 0.004 & 0.03 \\
& Spring & $0.017 \pm 0.004$ & 0.009 to 0.024 & 0.31 \\
& Summer & $0.018 \pm 0.004$ & 0.008 to 0.024 & 0.28 \\
& Autumn & $0.010 \pm 0.003$ & 0.005 to 0.015 & 0.29 \\
& Annual & $0.011 \pm 0.002$ & 0.005 to 0.015 & 0.30 \\
$1885-2008$ & Winter & $-0.009 \pm 0.004$ & -0.017 to 0.001 & 0.19 \\
& Spring & $0.015 \pm 0.006$ & 0.003 to 0.026 & 0.22 \\
& Summer & $0.004 \pm 0.005$ & -0.007 to 0.014 & 0.06 \\
& Autumn & $0.014 \pm 0.004$ & 0.006 to 0.023 & 0.30 \\
& Annual & $0.006 \pm 0.004$ & -0.001 to 0.013 & 0.15 \\
& & & & \\
\hline
\end{tabular}

(5) There are dips in the morning/evening series which are not replicated in the evening/morning series, such as the dip in the spring and summer morning series in the late $1860 \mathrm{~s}$ which lasted about 5 years, and the dip in the spring and summer evening series, which started about 1900 and lasted about 17 years. We have searched the metadata for this site to see if any change in observing practice occurred, such as a previously unnoticed shift in the time of the morning/evening readings, but have found nothing to which we can attribute these effects.

\section{Cyclic analysis of the humidity time series}

As a consequence of the apparent cyclic variability of $\mathrm{RH}$, we subject here both series to periodic analysis using the Wavelet techniques developed by Torrence and Compo, (1998). Wavelets are able to identify transient cyclic effects in time series and give an estimate of their significance. 

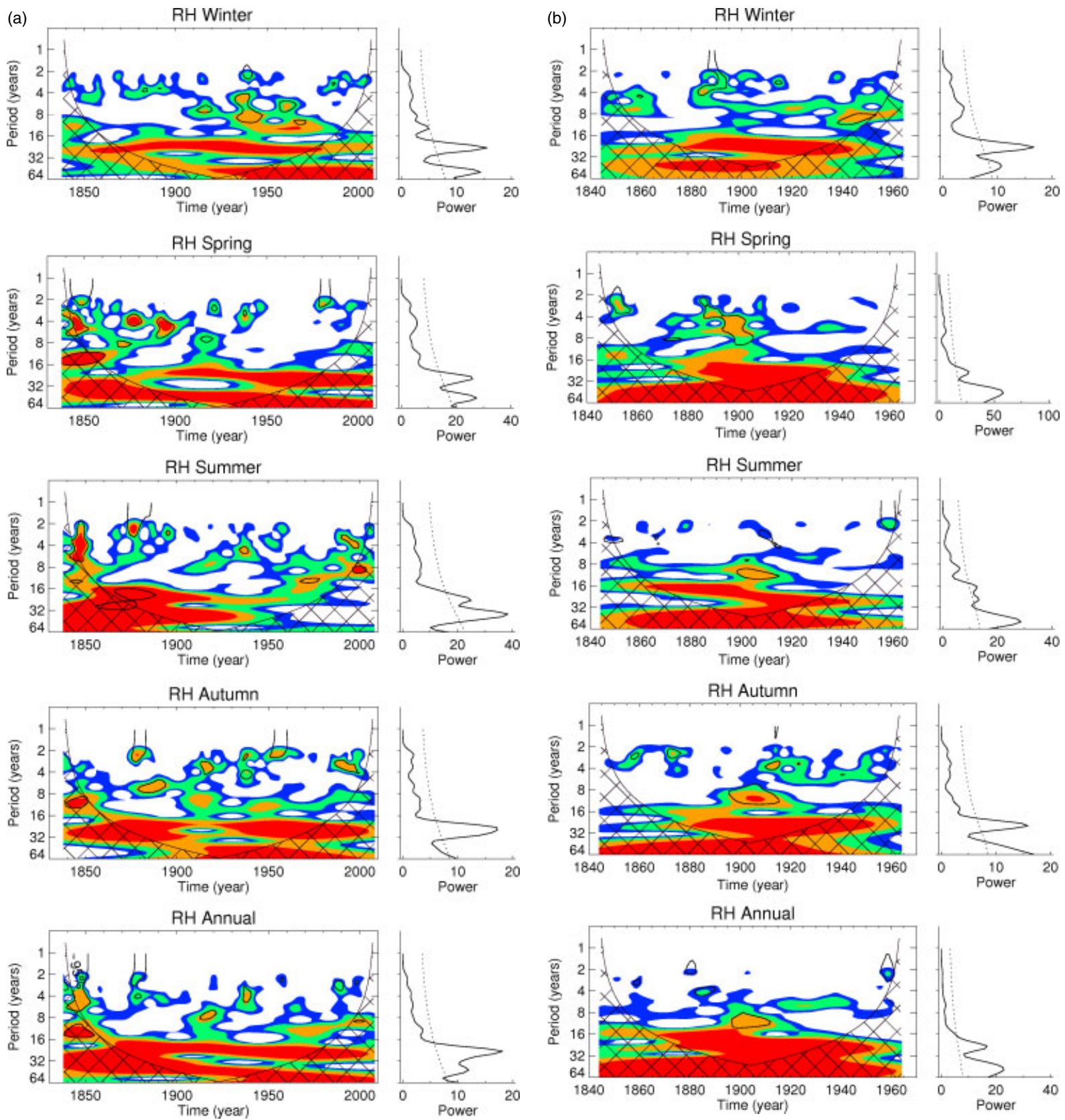

Figure 5. The wavelet power spectra for the mean seasonal and annual RH series: (a) at 09:00 GMT, 1838-2008; (b) at 21:00 GMT, 1844-1964. The large panels show the power plotted against period (vertical axis) and epoch (horizontal axis). The right-hand panels show the power, integrated over all epochs. The dotted line shows the 95\% confidence level (Torrence and Compo, 1998, for details). This figure is available in colour online at wileyonlinelibrary.com/journal/joc

In Figure 5, we show the two dimensional plots of wavelet power against period and time for the morning and evening RH series. The wavelet plots for three of the four seasons, namely winter, spring and summer, show a similar pattern with two periodicities present in both morning and evening series; the first ranging from 23 to 26 years, and the second from 36 to 51 years. In autumn, only the shorter period is present. For both morning and evening series, but particularly the evening, the second peak occurs in the hatched area of Figure 5 where the significance is reduced due to the finite length of the series. This limits our confidence in the validity of the longer period. The right-hand panels show the power integrated over time (equivalent to the power spectrum from the Fourier Transform) with dotted lines to indicate the 95\% confidence level. Here again, both periods are clearly evident. Owing to their presence in the hatched area in most of the evening plots and parts of the morning plots, the longer periods have reduced significance; however, their persistence over 3-4 cycles in some cases (e.g. spring and annual, morning and evening, summer, evening) would again suggest that they are real. The significance levels employed here are based on a comparison with random series with white and red noise spectra using Monte Carlo methods (Torrence and Compo, 1998). Our data have not been smoothed to enhance significance levels. 
Table IV. Periodicities and peak power of seasonal and annual $\mathrm{RH}$ series from wavelet analysis with a significance greater than $95 \%$.

\begin{tabular}{lccccc}
\hline \multirow{2}{*}{ Season } & \multicolumn{2}{c}{ AM } & & \multicolumn{2}{c}{ PM } \\
\cline { 2 - 3 } \cline { 5 - 6 } & Period (yrs) & Power & & Period (yrs) & Power \\
\hline \multirow{2}{*}{ Winter } & 23.4 & 15.4 & & 23.4 & 18.5 \\
& 51.0 & 13.1 & & 51.0 & 11.2 \\
Spring & 25.5 & 26.0 & & 24.5 & 26.5 \\
& 46.8 & 27.5 & & 46.8 & 58.5 \\
Summer & 23.4 & 24.9 & & 16.5 & 12.6 \\
& 36.0 & 38.4 & & 24.5 & 13.0 \\
& & & & 51.0 & 28.6 \\
Autumn & 24.5 & 17.1 & & 25.5 & 15.9 \\
Annual & 23.4 & 18.2 & & 24.5 & 16.5 \\
& & & & 49.0 & 22.8 \\
\hline
\end{tabular}

In Table IV, we list the periods that lie above the dotted line in Figure 5 together with the power extracted by the wavelet analysis. The shorter period with an average length of 24.3 years is clearly present in all seasons for both the morning and evening series. The second period, which ranges from 36 to 51 years and averages 46 years, is also present in the winter, spring and summer series, but not autumn, and again for both the morning and evening series. In several seasons, the longer period is close to double the shorter period. This could suggest that the longer period is an artefact and that the only true periodicity is the shorter one. However, a brief examination of the annual morning series in Figure 4(a), and the clearly defined peaks there at the longer intervals, suggests that the longer period has some degree of independent reality, other than a simple alias of the shorter period. This is confirmed in Table IV where the longer period is seen to have significantly higher power than the shorter period for the spring and summer, morning and evening, series.

Periodicities such as these have been noted in meteorological data before (Tabony, 1979; Burroughs, 1992) though they are seldom as clearly seen as those here. We have previously found (Butler et al., 1998; 2005a; 2007) periodicities close to $7-8,20-23$ and 30 years in rainfall, sunshine, air temperature and soil temperatures from Armagh. Wilson (1998) also found evidence for a 22-year periodicity in the Armagh temperature series. The 7-8-year periodicity is believed to derive from the North Atlantic Oscillation (NAO), which contains power at a similar frequency (McHugh and Rogers, 2001; Butler et al., 2007). However, for humidity, we find no significant correlation with the annual NAO Index in any season and only a weak correlation between the NAO Index and RH $(R=0.18$, prob. of occurrence by chance $\sim 5 \%$ ) for the winter months $(\mathrm{D}, \mathrm{J}, \mathrm{F})$, the season for which such correlations are usually strongest.

There is evidence from other studies for a 22-year periodicity in meteorological data. For example, Tsiropoula (2003) found a similar periodicity in the occurrence of storms and droughts, and Newell et al. (1989) in marine

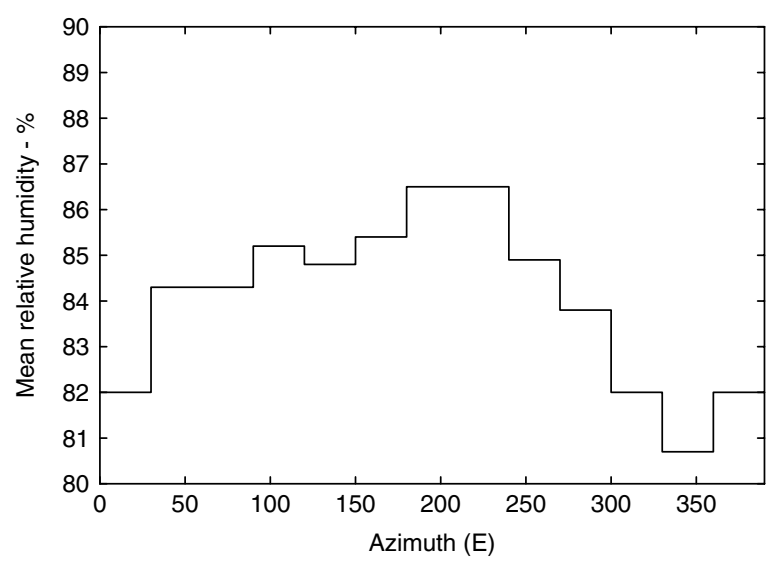

Figure 6. Mean RH at Armagh, in $30^{\circ}$ wide bands of azimuth, for the period 1900-2000 AD, plotted against the wind direction. Note the relatively high $\mathrm{RH}$ for southwesterlies and the low $\mathrm{RH}$ for northerlies.

temperatures. Multi-decadal variability in sea-surface temperatures in the North Atlantic region has been reviewed by Trenberth et al. (2007) and Randall et al. (2007), and references therein. Though the data series are usually too short for robust conclusions to be drawn, periodicities in the range 50-100 years, and amplitudes $0.4^{\circ} \mathrm{C}$ are indicated.

\section{Possible causes of the humidity cycles}

In the first instance, we explore the possibility that the humidity cycles derive from long time-scale changes in the atmospheric circulation over Ireland. We make a preliminary examination of some of the wind data for this site but must leave a full study until a later time. There is an enormous quantity of hourly wind speed and direction data from Armagh Observatory which derives from the Cup Anemometer developed there by Thomas Romney Robinson in the 1840s. This series, which lasts for well over a hundred years, has never been analysed and to do so is well beyond present resources. However, daily wind direction and force at 9 a.m. has been compiled for the period 1900-2000. Using this more restricted dataset, we explore the dependence of $\mathrm{RH}$ on wind direction (Figure 6). We note that the mean RH drops from $\sim 86 \%$, for southwesterly winds between 180 and $230^{\circ}$ azimuth, to $\sim 82 \%$ for northerly winds between 300 and $30^{\circ}$ azimuth. This would lead one to suspect that the cyclic change in humidity seen above could derive from longterm changes in circulation. To investigate this further, we correlate the mean annual RH with the number of days per annum with winds in these directions. We find a very weak correlation with the number of days with southerly winds $(R=0.14)$ but a stronger correlation with the number of days with northerly winds $(R=$ -0.38 ; probability of occurrence by chance $<0.1 \%$ ). Dry northerlies are a feature of the Irish climate in late January to June due partly to the influence of continental highpressure systems at this time of year (Rohan, 1986). It is also a period of relatively low sea-surface temperatures and reduced evaporation rates in the North Atlantic. 
The above study confirms that multi-decadal variations in atmospheric circulation are likely to be a contributory factor in the cyclic variability of RH at this site. The underlying cause of the circulation changes, however, remains uncertain.

A number of mechanisms which derive from natural oscillations in the atmosphere and large ocean basins of the Pacific and Atlantic have been proposed by Marshall et al. (2001), Delworth and Mann (2000) and Gallego and Cessi (2000) to explain the cyclic behaviour seen in meteorological parameters. These include variations in sea-surface temperature, ocean currents and atmospheric circulation patterns.

In a paper by Delworth et al. (1993) it was shown that coupled ocean/atmosphere models of the North Atlantic can exhibit irregular oscillations with multi-decadal periods of approximately 50 years duration. These oscillations originate in density anomalies in the sinking region of the thermohaline circulation, between 52 and $72^{\circ} \mathrm{N}$, and bear some resemblance to those seen in our $\mathrm{RH}$ series. With the prevailing westerlies, passing over these regions and crossing the Atlantic, it is feasible that such oscillations could affect relative humidity over Ireland.

Both the Pacific and Atlantic Oceans have preferred natural multi-decadal oscillations (e.g. the PDO and AMO, see Trenberth et al., 2007) that depend on the geometry of the oceans and influence the atmospheric temperature, pressure and circulation patterns as well as subsurface ocean currents. Taking these models further, to the global scale, it has been suggested by Gallego and Cessi (2001) that more extensive oscillations may develop which involve interaction between the Pacific and Atlantic, via the connecting atmosphere, with a characteristic period of $\sim 38$ years, close to the longer of the two periodicities seen in our RH data.

The shorter of the two periodicities, which varies from 23 to 26 years in the wavelets, is similar in length to the solar magnetic cycle ( $\sim 22$ years). Though many studies have suggested links between the sunspot 11-year cycle and climate variables (e.g. Currie, 1993; Wilson, 1998), relatively few have reported a correspondence with the Hale 22-year magnetic cycle. Several studies (e.g. by Svensmark and Friis-Christensen, 1997; Pallé and Butler, 2000, 2004; Marsh and Svensmark, 2000, 2003) have pointed to correlations between global cloud cover and the flux of cosmic rays which are known to be strongly modulated by the Sun's magnetic field. Physical models of how cloud cover could be influenced by cosmic rays via ionisation in the atmosphere, (though as yet unproven), have been presented by Tinsley and Yu (2004). Should the link between cloud cover and cosmic rays be confirmed, we may expect to find solar-like cycles in other meteorological variables linked to water vapour and clouds.

\section{Conclusions}

We have presented a series of calibrated RH measurements from Armagh Observatory in Northern Ireland.
This series, which is believed to be the longest published so far, should, due to the rural nature of the station and its proximity to the Atlantic Ocean, be of particular interest to climatologists.

The wet-bulb and dry-bulb temperature readings, on which the series are based, have been carefully vetted for errors and inconsistencies and corrections have been made for all known sources of inhomogeneity, including the time of observation. The morning series extends for the full period 1838-2008, whereas, the evening series stops in 1965 . For this maritime climate station, approximately $99 \%$ of the daily $\mathrm{RH}$ values lie in the range 60-100\%. An unexplained, apparent, discontinuity in the seasonal and annual mean $\mathrm{RH}$ in the evening around 1900 , limits the usefulness of this shorter dataset. However, there is no apparent discontinuity in the morning series which we believe to be robust to instrumental and calibration errors.

We find the mean annual RH at 09:00 GMT to have only a small and barely significant long-term trend since 1885 . This result is consistent with one of the common assumptions made in climate models (Randall et al., 2007); namely that RH has been held constant by the hydrological cycle, whilst tropospheric temperatures have risen over the past century. Recent work on global specific humidity (Willett et al., 2007) has indicated that the amount of water vapour contained in the atmosphere has increased in parallel with temperatures in recent decades. If RH has remained constant in Northern Ireland since the late 19th century, as our results suggest, whilst temperatures have risen, a similar increase in Specific Humidity would be expected here too. Future work on specific humidity from the Armagh wet-bulb and dry-bulb readings is planned to investigate these suggestions.

There are strong periodicities present in the Armagh seasonal mean RH, which are clearly evident in the annual time series and are confirmed by wavelet analysis. The shortest period $\sim 24$ years is close to periodicities found previously in air temperature, rainfall, hours of bright sunshine, and soil temperatures at Armagh. The longer period of 36-51 years, which is present in all seasons, except autumn, and in both the evening and morning RH series, has not been found in other meteorological data for this site. In the annual series, this periodicity looks non-sinusoidal, with rather a steep rise to a higher level, which lasts for around 7 years, followed by a decline to a level about $3 \%$ lower which lasts for 30-40 years.

Two 19th century peaks in RH, seen most clearly in the mean annual morning series, coincide with serious infestations of potato blight in Ireland. The earlier peak in 1846 was most likely a contributory cause of the Great Irish Famine. We note that, as the most recent sustained increase in RH began in 1964 and the mean period between the three previous increases in $\mathrm{RH}$ is 42 years, a similar excursion to higher $\mathrm{RH}$ levels, which could last for approximately 7 years, may be imminent.

Whilst we cannot draw firm conclusions from the data for just one site, it seems likely that the immediate 
explanation for these cycles may be found in long-term atmospheric circulation changes over Ireland. Beyond this, we have speculated whether the underlying causes of such changes may lie in the thermohaline circulation of the North Atlantic or an interaction between the Atlantic and Pacific Oceans. Any conclusions must be highly speculative at this stage and they are included here in the hope that they might spur further work on historical humidity series which, currently, are a rather understudied aspect of climate change.

\section{Acknowledgements}

We thank A. D. S. Coughlin, D. Cardwell, D. Boyle, G. Ryan and L. Dougan for their assistance with entering the raw wet-bulb and dry-bulb temperature readings into computer file; E. Pallé for suggestions on a previous version of the manuscript; and E. Warrick and P. Clews of the UK Meteorological Office for the RH data from Loughall. This work received financial support from the Heritage Lottery Fund and The Irish Soldiers and Sailors Land Trust. Research at Armagh Observatory is grant aided by the Department of Culture, Arts and Leisure for Northern Ireland.

\section{References}

Buck AL. 1981. New equations for computing Vapour Pressure and Enhancement Factor. Journal of Applied Meteorology 20: $1527-1532$.

Burroughs WJ. 1992. Weather Cycles, Real or Imaginary. Cambridge University Press: Cambridge.

Butler CJ, Hoskin MA. 1987. The archives of Armagh Observatory. Journal of the History of Astronomy 18: 295-307.

Butler CJ, Coughlin ADS, Fee DT. 1998. Precipitation at Armagh Observatory 1838-1997. Biology and Environment: Proceedings of the Royal Irish Academy 98B, 123-140.

Butler CJ, García-Suárez AM, Coughlin ADS, Morrell C. 2005a. Air Temperatures at Armagh Observatory, N. Ireland from 1796-2002. International Journal of Climatology 25: 1055-1079.

Butler CJ, García-Suárez AM, Coughlin ADS, Cardwell D. 2005b. Meteorological Data recorded at Armagh Observatory: Vol. 2. Daily, Mean Monthly, Seasonal and Annual, Maximum and Minimum Temperatures, 1844-2004. Armagh Observatory Climate Series.

Butler CJ, Coughlin ADS, Johnston DJ, Cardwell D, Morrell C. 2005c. Meteorological Data recorded at Armagh Observatory: Vol. 6. Daily, Mean Monthly, Seasonal and Annual, Air Temperatures from Series I (1796-1882), including the Dunsink Patch (1825-1833), and Series III (1844-1964). Armagh Observatory Climate Series.

Butler CJ, Emerson M, García-Suárez AM, Pallé E, Kelly ST. 2005d. Meteorological Data recorded at Armagh Observatory: Vol. 10. Daily, Monthly, Seasonal and Annual Hours of Bright Sunshine, 1880-2004. Armagh Observatory Climate Series.

Butler CJ, García-Suárez AM, Pallé E. 2007. Trends and Cycles in long Irish Meteorological Series, Biology and Environment: Proceedings of the Royal Irish Academy 107B, 157-165.

Butler CJ, García-Suárez AM. 2010. Meteorological Data recorded at Armagh Observatory: Vol. 13. Daily, Mean Monthly, Seasonal and Annual Humidity, 1838-2008, corrected for the time of observation. Armagh Observatory Climate Series.

Coughlin ADS, Butler CJ. 1998. Is Urban Spread affecting the Mean Temperature at Armagh Observatory. Irish Astronomical Journal 25 : $125-128$.

Currie RG. 1993. Luni-solar 18.6 and 10-11 year signal in USA air temperature records. International Journal of Climatology 13 $31-50$.

Delworth TL, Manabe S, Stouffer RJ. 1993. Interdecadal variations of the Thermohaline Circulation in a coupled Ocean-Atmosphere Model. Journal of Climate 6: 1993-2010.
Delworth TL, Mann ME. 2000. Observed and simulated multidecadal variability in the Northern Hemisphere. Climate Dynamics 16: 661-676.

Gallego B, Cessi P. 2000. Exchange of heat and momentum between the atmosphere and the ocean: a minimal model of decadal oscillations. Climate Dynamics 16: 479-489.

Gallego B, Cessi P. 2001. Decadal variability of two oceans and an atmosphere. Journal of Climate 14: 2815-2832.

García-Suárez AM, Butler CJ, Cardwell D, Coughlin ADS, Donnelly A, Fee DT, Hickey KR, Morrow B, Taylor T. 2002. Meteorological Data recorded at Armagh Observatory: Vol. 1. Daily, Monthly and Annual Rainfall 1838-2001. Armagh Observatory Climate Series.

García-Suárez AM, Butler CJ, Morrow B. 2005. Meteorological Data recorded at Armagh Observatory: Vol. 4. Daily, Mean Monthly, Seasonal and Annual, Soil Temperatures, 1904-2002. Armagh Observatory Climate Series.

García-Suárez AM, Park E, Butler CJ, Hickey KR, Grant A. 2005. Meteorological Data recorded at Armagh Observatory: Vol. 3. Metadata, 1796-2006. Armagh Observatory Climate Series.

García-Suárez AM, Butler CJ. 2006. Soil Temperatures at Armagh Observatory, Northern Ireland, from 1904 to 2002. International Journal of Climatology 26: 1075-1089.

García-Suárez AM, Butler CJ, Coughlin ADS, Cardwell D, Boyle E, Ryan G, Dougan L. 2007. Meteorological Data recorded at Armagh Observatory: Vol. 7. Daily, Mean Monthly and Mean Annual Wetbulb and Dry-bulb Temperatures and Relative Humidity 1844-2006. Armagh Observatory Climate Series.

Harrison LD. 1965. Fundamental concepts and definitions relating to Humidity and Moisture. In Measurement and Control in Science and Industry. Wexler A (ed). Reinhold: New York; 3: 3-69.

Held IM, Soden BJ. 2000. Water vapor feedback and global warming. Annual Review of Energy and the Environment 25: 441-475.

Jensen ME, Burman RD, Allen RG. 1990. Evapotranspiration and irrigation water requirements. ASCE Manuals and Reports on Engineering Practice No. 70.

Kiehl JT, Trenberth KE. 1997. Earth's Annual Global Mean Energy Budget. Bulletin American Meteorological Society 78: 197-208.

Manabe S, Wetherald RT. 1967. Thermal Equilibrium of the atmosphere with a given distribution of relative humidity. Journal of Atmospheric Sciences 24: 241-259.

Marsh ND, Svensmark H. 2000. Low cloud properties influenced by Cosmic Rays. Physics Review Letters 85: 5004-5007.

Marsh ND, Svensmark H. 2003. Solar influence on Earth's climate. Space Science Reviews 107: 317-325.

Marshall J, Kushnir Y, Battisti D, Chang P, Czaj A, Dickson R, Hurrell J, McCartney M, Saravanan R, Visbeck M. 2001. North Atlantic Climate Variability: Phenomena, Impacts and Mechanisms. International Journal of Climatology 21: 1863-1898.

McHugh MJ, Rogers JC. 2001. North Atlantic oscillation influence on precipitation variability around the southeast African convergence zone. Journal of Climate 14: 3631-3642.

Murphy DM, Koop T. 2005. Review of the vapour pressures of ice and supercooled water for atmospheric applications. Quarterly Journal Royal Meteorological Society 131: 1539-1565.

Newell NE, Newell RE, Hsuing J, Zhongxian W. 1989. Global Marine Temperature variation and the solar magnetic cycle. Geophysical Research Letters 16: 311-314.

ÓGráda C. 1989. The Great Irish Famine. Cambridge University Press: Cambridge.

Pallé E, Butler CJ. 2000. The Influence of Cosmic Rays on Terrestrial Clouds and Global Warming. Astronomy and Geophysics 41: 4.18-4.22.

Pallé E, Butler CJ. 2001. Sunshine records from Ireland: Cloud factors and possible links to Solar Activity and Cosmic Rays. International Journal of Climatology 21: 709-729.

Pallé E, Butler CJ. 2004. The possible connection between Ionisation in the Atmosphere by Cosmic Rays and Low-level Clouds. Journal of Atmospheric and Solar-Terrestrial Physics 66: 1779-1790.

Randall DA, Word RA, Bony S, Colman R, Fichefet T, Fyfe J, Kattsov V, Pitman A, Shukla J, Srinivasan J, Stouffer RJ, Sumi A, Taylor KE. 2007. Climate Models and their Evaluation. In: Climate Change 2007: The Physical Science Basis. Contribution of Working Group I to the Fourth Assessment Report of the Intergovernmental Panel on Climate Change. Solomon S, Qin D, Manning M, Chen Z, Marquis M, Averyt KB, Tignor M, Miller HL (eds). Cambridge University Press: Cambridge, UK and New York, USA.

Rohan PK. 1986. The Climate of Ireland. Government Publications: Dublín. 
Scott RH. 1874-1883. Hourly Readings from the Self-Recording Instruments at the Seven Observatories in connection with the Meteorological Office. Published monthly 1874-1880 and quarterly 1881-1883. UK Meteorological Office.

Soden BJ, Jackson DL, Ramaswamy V, Schwarzkopf MD, Huang X. 2005. The radiative signature of upper tropospheric moistening. Science 310: 841-844.

Svensmark H, Friis-Christensen E. 1997. Variations of Cosmic Ray Flux and global cloud coverage. A missing link in solar-climate relationships. Journal of Atmospheric and Solar-Terrestrial Physics 59: $1225-1232$.

Tabony RC. 1979. A spectral filter analysis of long period records in England and Wales. Meteorological Magazine 108: 102-112.

Tinsley BA, Yu F. 2004. Atmospheric Ionization and Clouds as links between Solar Activity and Climate. In Solar Variability and its effects on Climate. AGU Geophysical Monograph 141, Pap JM, Fox P (eds). American Geophysical Union. 321-339.

Torrence C, Compo GP. 1998. A practical Guide to Wavelet Analysis. Bulletin of American Meteorological Society 79: 61-78.

Trenberth KE, Jones PD, Ambenje P, Bojariu R, Easterling D, Klein Tank A Parker D, Rahimzadeh F, Renwick JA, Rusticucci M, Soden B, Zhai P. 2007. Observations: Surface and Atmospheric Climate Change. In Climate Change 2007: The Physical Science
Basis. Contribution of Working Group I to the Fourth Assessment Report of the Intergovernmental Panel on Climate Change. Solomon S, Qin D, Manning M, Chen Z, Marquis M, Averyt KB, Tignor M, Miller HL (eds). Cambridge University Press: Cambridge, UK and New York, USA.

Tsiropoula G. 2003. Signatures of solar activity in meteorological parameters. Journal of Atmospheric and Solar-Terrestrial Physics $\mathbf{6 5}$ 469-482.

Tyndall J. 1861. On the absorption and radiation of heat by gases and vapours and of the physical connexion of radiation, absorption and conduction. The London, Edinburgh and Dublin Philosophical Magazine and Journal of Science 22: 169-194, 273-285.

UKMO Hygrometric Tables. 1964. Meteorological Office Hygrometric Tables: Part II Stevenson Screen Readings, Degrees Celsius. Met.O. 265b. Her Majesty's Stationery Office: London.

Vomel H. 2010. Saturation vapour pressure formulations. CIRES, Boulder. (http://cires.colorado.edu/ voemel/vp.html).

Willett KM, Gillett NP, Jones PD, Thorne PW. 2007. Attribution of observed surface humidity changes to human influence. Nature 449 : 710-712.

Wilson RM. 1998. Evidence for solar cycle forcing and secular variations in the Armagh Observatory temperature record, 1844-1992. Journal of Geophysical Research 103(D10): 11,159-11,171. 